\title{
Procesos de exclusión social severa: de la escuela a la calle ${ }^{1}$
}

\section{Gabriel Robles Gavira}

Área de Trabajo Social y Servicios Sociales, Delegación Municipal de Asuntos Sociales, Ayuntamiento de Cádiz Facultad de Derecho, Universidad de Cádiz

<gabriel.roblesgavira@cadiz.es>

\section{Ana Beatriz Pérez González}

Área de Sociología, Facultad de Ciencias de la Educación, Universidad de Cádiz

Gure gizarteetan gero eta sarriagotan ezagutzen da bazterketaren tokia, izan ere, bidaiarien erritmo konstante bat mantentzen baita, betiere asmo dutelarik askotan lortzen ez den egokitze ekonomikoa izatea. Baina pertsona horientzat arazo gertatzen da ez jakitea noiz utziko dioten horrela bizitzeari. Artikulu honetan azaltzen denez, bide askoren artetik, askotan gertatzen da horren irteera edo geldiune izatea absentismoa, eskola-porrota eta eskola uztea. Ikerketa honen xede da erakusten saiatu eta erakustea zeintzuk diren kontzeptu horien eta gizarte-bazterketaren arteko erlazio kausalak. Hezkuntza-faktore horien guztien elkartzeak azalduko luke gizarte-bazterketaren fenomenoaren izaera berri bat, eta baliteke argiago ezagutaraztea ohiko azterlanetan ilunpean gelditzen diren guneak.

\section{GAKO-HITZAK:}

Haurtzaroa, bazterketa, eskola-absentismoa, eskolaporrota, etxegabeko pertsonak.
Exclusión es un lugar que cada vez está más frecuentado en nuestras sociedades, porque mantiene un ritmo constante de viajeros que pasan momentáneamente con la intención de buscar un acomodo económico que no siempre logran. Pero un problema de estas personas es que no siempre saben cuándo saldrán de esa situación. En el presente artículo se plantea que uno de los puntos de partida o paradas importantes en el camino, entre otros muchos, es el absentismo, el fracaso escolar y el abandono escolar. El objetivo de esta investigación es tratar de mostrar y demostrar las relaciones causales entre estos conceptos y la exclusión social. Esa conjunción de factores educativos definiría un nuevo carácter del fenómeno de la exclusión social, descubriendo quizá más claramente zonas ocultas en los análisis habituales.

\section{Palabras Clave:}

Infancia, exclusión, absentismo escolar, fracaso escolar, personas sin hogar.

${ }^{1}$ Una versión previa de este artículo se presentó como comunicación en el IV Encuentro Internacional con Menores en Contextos de Riesgo, celebrado en Tetuán en 2012 (Pérez-González y Robles Gavira, 2012). 


\section{Introducción}

Exclusión es un lugar que cada vez está más frecuentado en nuestras sociedades, porque mantiene un ritmo constante de viajeros. La utilización del término viajero es, en este caso, consciente, porque, como cuenta Paul Bowles (1992: 13):

Mientras el turista se apresura por lo general a regresar a su casa al cabo de algunos meses o semanas, el viajero, que no pertenece más a un lugar que al siguiente, se desplaza con lentitud durante años de un punto a otro de la tierra.

Ése es el gran problema de estas personas, que no saben cuando saldrán de Exclusión. Es un lugar al que se llega después de un largo viaje, que puede surgir en muchos orígenes y por diversas causas. Es un viaje que también está lleno de paradas, que pueden ser una oportunidad de mejora o el impulso imparable hacia un destino de exclusión.

En este trabajo se plantea que uno de los puntos de partida o paradas importantes en el camino, entre otros muchos, es el absentismo, el fracaso escolar y el abandono escolar. El objetivo de esta investigación es tratar de mostrar y demostrar las relaciones causales entre estos conceptos y la exclusión social. Esa conjunción de factores educativos definiría un nuevo carácter del fenómeno de la exclusión social, descubriendo quizá más claramente zonas ocultas en los análisis habituales.

El fenómeno de la exclusión ha cambiado: de una sociedad donde predominaban relaciones de desigualdad y subordinación vertical, hemos pasado a una sociedad donde tiende a predominar una nueva lógica de polarización en términos de dentro/fuera. Además, a la relajación de los sistemas de cobertura del Estado del Bienestar se une la profunda crisis económica internacional que está sufriendo el sistema capitalista. Esto implica, entre otros aspectos, profundizar en la brecha de un nuevo conjunto de colectivos excluidos, o en la ruptura de ciertos parámetros básicos de integración social, y situar en las zonas de vulnerabilidad a una variedad amplia de grupos sociales (Tezanos, 2008: 3). Las personas sin hogar representarían un caso extremo dentro de la exclusión social.

\section{Metodología}

Para abordar la problemática de esta investigación, lo metodológicamente idóneo sería realizar un estudio longitudinal con una muestra de niños/as o adolescentes absentistas que hayan tenido episodios de fracaso escolar que derivasen en el abandono del sistema educativo. Una mirada retrospectiva de estas personas sin hogar nos daría pistas de cuáles han sido los factores de riesgo presentes y los más comunes entre ellos, qué sucesos vitales estresantes han provocado fracturas en sus recorridos vitales, $y$ por último, qué sinergias entre los factores de riesgo temprano, sucesos vitales estresantes y trayectorias vitales han hecho que estas personas terminen engrosando las filas de la exclusión social severa.

Sin embargo, hasta ese momento esta investigación pretende acercarse desde un abordaje indirecto a este fenómeno tan complejo por la presencia tanto de condicionantes sociales como individuales. Primero, comparando los factores de riesgo de la exclusión y el absentismo escolar, para encontrar sus procesos comunes. Segundo, profundizando en los sucesos vitales estresantes que han podido marcar una y otra trayectoria. En efecto, en investigaciones sobre las personas sin hogar, se comprueba cómo, en los primeros años de vida, han sufrido malos tratos, problemas de drogas en los padres, abandono del menor, abandonos del hogar por los padres, estancia en un orfanato o fugas del hogar (Cabrera, Malguesini y López, 2002: 175-177).

Un primer paso sería definir las poblaciones de estudio. Primero, desde el campo de la educación, debe recordarse que se considera absentismo la falta de asistencia regular y continuada del alumnado de educación básica y obligatoria a los centros docentes donde se encuentran escolarizados, sin motivo de enfermedad o causa mayor que lo justifique (Junta de Andalucía, 2003). El fracaso escolar se basaría en las dificultades para alcanzar los objetivos marcados por el sistema educativo. Finalmente, el abandono sería el efecto final del proceso -y el menos deseable-, la retirada del individuo del sistema educativo (Fernández Enguita, Mena y Riviere, 2010: 19-20).

Por otro lado, el concepto de exclusión social se define como todas aquellas personas, colectivos o familias que, en algún sentido, se encuentran fuera de las oportunidades vitales que definen una ciudadanía social plena en las sociedades contemporáneas. Se trata de procesos sociales que adoptan diversas fases e implican limitaciones en el nivel de participación ciudadana y en el acceso a los recursos sociales. Conlleva estados anímicos de pérdida de identidad, infravaloración personal y desmotivación vital. Comprende privación del ejercicio de derechos sociales básicos. Puede recorrer la trayectoria vital de un individuo/familia a lo largo de su vida y ser un estado permanente. Dentro de la gran variabilidad de situaciones de vulnerabilidad y riesgo social que existen, se optará por delimitar al colectivo de estudio a través de la categoría A (sin techo) de la Tipología Europea de Sin Hogar y Exclusión Residencial ETHOS (Feantsa, 2005).

Para comparar los datos y sacar las conclusiones pertinentes, el estudio se centrará en la Encuesta a las Personas sin Hogar de $\mathbf{2 0 1 2}$ del Instituto Nacional de Estadística (INE). También se consultarán otras encuestas del INE que pudieran estar relacionadas con esta problemática, como la Encuesta de Condiciones de Vida. El ámbito de la exclusión presenta más dificultades a la hora de encontrar series de encuestas específicas en las que se pueda apreciar una evolución y hacer comparaciones. Se hace 
necesario, por tanto, recurrir a datos que, de forma indirecta, nos den pistas sobre las implicaciones de los dos fenómenos.

No ocurre así en el campo de la educación, que sí presenta series de datos con más largo recorrido y de diferentes instituciones. En este caso, se pueden encontrar series y datos sobre fracaso y abandono escolar en el INE, la Encuesta de Transición Educativoformativa e Inserción Laboral (ETEFIL), pero también en los informes PISA o en el Sistema Estatal de Indicadores de Educación. Por otro lado, a escala local, contamos con los datos del Programa de Absentismo Escolar y del Centro de Acogida Municipal de la Delegación Municipal de Asuntos Sociales del Ayto. de Cádiz (Tabla 1). También se han llevado a cabo entrevistas al personal de los distintos servicios.

El objetivo es enlazar las dos fuentes de datos de poblaciones diferentes con la experiencia a lo largo de más de una década de intervenciones en los dos dispositivos señalados. Estas entrevistas armarán una transición entre ambas series de datos y aportarán un enfoque cualitativo a la investigación. La Tabla 1 muestra los datos totales de los/as niños/as incluidos en el Programa.

\section{Algunos datos sobre el problema de la exclusión}

Durante 2011, España tuvo un índice de Gini superior al 0,34, situándose de nuevo entre los países con mayor desigualdad de Europa. En concreto, era el país europeo donde mayor era la distancia entre el $10 \%$ de la población con mayor renta y el $10 \%$ de la población con menores ingresos: si esta última tenía una participación del 1,6\% de los ingresos, la población más rica tenía acceso a casi un $25 \%$ de la renta. Además, los datos de entre 2004 y 2011 muestran cómo la décima parte de las personas más pobres redujeron su participación en la renta total en un $38,5 \%$. Sin embargo, el $10 \%$ más rico vio aumentar, aunque fuera ligeramente, su renta en un 2,5\% (Muñoz del Bustillo, 2013: 25-28). Como consecuencia de todo lo anterior, en pocos años España ha pasado de encontrarse entre los puestos 9 y 10 en el
Índice de Desarrollo Humano de la ONU a hacerlo en los puestos 22-23.

En España, la tasa de pobreza ha llegado a superar el $21 \%$, con determinados sectores de población, como las familias numerosas y monoparentales y los hogares con una persona mayores de 65 años donde la pobreza ha alcanzado niveles del $40 \%$. Las Encuestas sobre Condiciones de Vida de 2009 a 2012 confirman una tendencia creciente en la tasa de pobreza, que ha pasado del $19,5 \%$ al $21,1 \%$.

En cuanto al desempleo, los datos y las tendencias de la Encuesta de Población Activa (INE, 2012) no permiten ser muy optimistas. El nivel de paro juvenil se ha situado en el $50 \%$. Más de un millón y medio de familias tenían a todos sus miembros en desempleo. Los parados de larga duración han pasado del $\mathbf{2 3 , 7} \%$ en 2007 al 48,2 \% en 2011, es decir, se han duplicado. Para terminar, el sistema de protección al desempleo ha reducido su cobertura de cerca del $80 \%$ al $63,4 \%$ en 2012.

Cáritas, por ejemplo, pasó de atender a 350.000 personas en 2007 a llegar a más de un millón en 2011 (Cáritas Española, 2012). En 2012, se atendió a cerca de 23.000 personas en centros asistenciales de alojamiento y restauración (INE, 2012a). La mayor parte de estas personas eran hombres, menores de 45 años y españoles. El $50 \%$ se contabilizaron en Cataluña, Madrid y Andalucía, las únicas comunidades autónomas que sobrepasaron el $10 \%$. Cerca de la mitad llevaba más de tres años viviendo en la calle y la mitad tenía hijos. En cuanto a las causas que provocaron su situación, 9 de cada 10 lo achacaban a tres motivos: la pérdida de trabajo ( $45 \%$ ), no poder pagar el alojamiento (26\%) y la separación de su pareja (21\%).

En el caso de Cádiz, durante 2012 el Centro de Acogida Municipal atendió a 840 personas (Delegación Municipal de Asuntos Sociales, 2012a). De éstas, más de 800, pernoctaron un total de 6.595 días en el Centro. Por otro lado, el Centro de Día 'Luz y Sal’, de Cáritas, atendió a 121 personas (Cáritas Diocesana de Cádiz y Ceuta, 2012).

La exclusión social severa tiene nombre de varón. El $90 \%$ de las personas que pasaron por ambos

Tabla 1. Casos atendidos en el Programa de Absentismo Escolar del Ayto. de Cádiz, por curso escolar (2008/09/-2012/13)

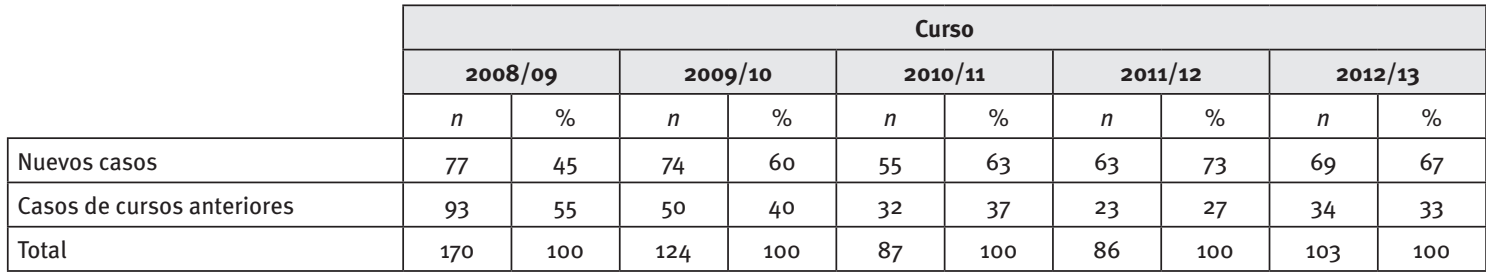

Fuente: Elaboración propia a partir de Delegación Municipal de Asuntos Sociales (2012b). 
recursos eran hombres. Esta relación es constante desde hace varios años. El número de parejas era muy reducido, poco más de 10. Casi todos y todas eran españoles, y el resto se repartía entre toda una gama de nacionalidades de todo el mundo, sobre todo, europeas. Estos datos se mantienen para las dos instituciones (ibídem; Delegación Municipal de Asuntos Sociales, 2012a). No obstante, el trabajo de 'Luz y Sal' se basa en un proceso integral a largo plazo para modificar valores, actitudes y comportamientos de cara a una integración total y estable. En este caso, iniciaron un proceso de valoración 73 ciudadanos y se trabajaron procesos de larga estancia con 21 (Cáritas Diocesana de Cádiz y Ceuta, 2012).

Generalmente, son personas con un nivel de instrucción y educativo bajo (alrededor del $70 \%$ ), y, por tanto, su carrera laboral ha estado asociada a empleos de baja cualificación, que son los más vulnerables ante la crisis. No tienen ingresos o, si existen, son muy reducidos y se limitan a las rentas mínimas de inserción, salario social, pensiones no contributivas, renta activa de inserción o prestaciones similares. Carecen de redes sociales de apoyo y recursos. Otro aspecto muy importante es su estado de salud: un $25 \%$ de las personas que pasan por el Centro de Acogida Municipal tienen problemas serios de salud, ya sean enfermedades graves 0 crónicas. Las más frecuentes están relacionadas con la salud mental y las secuelas del consumo abusivo de drogas.

\section{Dimensiones del fenómeno}

La exclusión social y del fracaso escolar son consecuencia de una multiplicidad de factores que actúan de forma interrelacionada. Requieren de una interpretación que conecte las esferas relacionadas con la persona, sus relaciones y redes sociales con la cultura en la que está inserta, y por último, y más importante, con las estructuras de desigualdad económica. Para situarnos en el contexto de la exclusión de las personas sin hogar, del absentismo y del fracaso escolar de estos jóvenes, nos centraremos en estas tres dimensiones, adaptándolas al contexto de la ciudad de Cádiz, por ser nuestro ámbito de estudio y trabajo. Sin embargo, ello no es óbice para que se tengan presentes las tendencias generales, como referencia de cara a anticipar posibles escenarios futuros y cambios en los perfiles y las dinámicas de la exclusión.

El Cuadro 1 muestra las causas del sinhogarismo, las variables que influyen en este fenómeno y los posibles desencadenantes de una situación de exclusión social severa. Seguramente, existen muchos más factores y desencadenantes de la situación de sinhogarismo, pero para el presente estudio este cuadro refleja con suficiente exactitud las variables que nos podemos encontrar en las situaciones estudiadas. Sobre todo, incluye aquellas situaciones que relacionan fracaso y abandono escolar con la exclusión social extrema.

\begin{tabular}{|l|l|l|}
\hline $\begin{array}{l}\text { Cuadro 1. Causas del sinhogarismo, factores que influyen } \\
\text { en este fenómeno y variables que lo desencadenan }\end{array}$ \\
\hline $\begin{array}{l}\text { Dimensiones/ } \\
\text { causas del } \\
\text { sinhogarismo }\end{array}$ & Factores implicados & $\begin{array}{l}\text { Desencadenantes de la } \\
\text { situación }\end{array}$ \\
\hline \multirow{5}{*}{ Estructural } & Desempleo/pobreza & $\begin{array}{l}\text { Falta de recursos } \\
\text { económicos }\end{array}$ \\
\cline { 2 - 3 } & $\begin{array}{l}\text { Culturales/raciales/ } \\
\text { étnicos }\end{array}$ & $\begin{array}{l}\text { Cierre del mercado } \\
\text { laboral }\end{array}$ \\
\cline { 2 - 3 } & Vivienda & Impago/desalojo \\
\hline \multirow{5}{*}{ Relacional } & $\begin{array}{l}\text { Desestructuración } \\
\text { familiar }\end{array}$ & $\begin{array}{l}\text { Salida del domicilio } \\
\text { familiar }\end{array}$ \\
\cline { 2 - 3 } & Situación relacional & Violencia \\
\cline { 2 - 3 } & Rupturas & $\begin{array}{l}\text { Salida del domicilio } \\
\text { familiar, aislamiento, } \\
\text { soledad }\end{array}$ \\
\hline \multirow{5}{*}{ Individual } & $\begin{array}{l}\text { Discapacidad/ } \\
\text { enfermedad crónica }\end{array}$ & $\begin{array}{l}\text { Consecuencias de la } \\
\text { enfermedad }\end{array}$ \\
\cline { 2 - 3 } & $\begin{array}{l}\text { Dificultades/ } \\
\text { limitaciones de } \\
\text { aprendizaje }\end{array}$ & $\begin{array}{l}\text { Problemas } \\
\text { socioeconómicos }\end{array}$ \\
\cline { 2 - 3 } & $\begin{array}{l}\text { Sucesos vitales } \\
\text { estresantes }\end{array}$ & $\begin{array}{l}\text { Trastornos psicológicos } \\
\text { y deterioro físico y } \\
\text { social }\end{array}$ \\
\hline
\end{tabular}

Fuente: Elaboración propia a partir de Federación de Entidades de Apoyo a las Personas sin Hogar (2011).

\section{Resultados en relación con las dimensiones}

\subsection{Dimensión estructural}

Esta primera dimensión abarca aquellas situaciones que se pueden enmarcar dentro del espacio de la economía. Una parte importante de los estudios sobre la exclusión ahondan en la centralidad del empleo, es decir, su carencia como factor fundamental de los procesos de exclusión. La exclusión del empleo como causa de una serie considerable de otras carencias como la vivienda, la educación o la calidad de vida. El trabajo es otro instrumento principal, y casi exclusivo, de inserción social.

Esta centralidad absoluta del empleo en nuestras sociedades tiene un matiz perverso. Las características de la sociedad informacional y posfordista superan la noción tradicional del trabajo y las condiciones laborales. Este nuevo modelo se encamina hacia un mercado y una sociedad duales: se precisan trabajadores altamente cualificados y preparados para las labores de diseño, programación, informatización, improvisación o creatividad; en cambio, otro tipo de trabajadores poco especializados, con bajos niveles educativos, formativos y de cualificación, se conciben como fácilmente sustituibles e intercambiables, ya sea por trabajadores con condiciones más precarias, por robots o por sistemas automatizados (Tezanos, 2008: 162-163).

En esta situación, niños/as y jóvenes con carencias educativas y formativas son candidatos privilegiados a engrosar las filas de la exclusión. La ausencia o deficiente escolarización representa la exclusión del sistema educativo y, por añadidura, la exclusión del 
individuo en el futuro en los ámbitos social y laboral (Subirats, 2005: 72-73). Ya en el informe Foessa de 1998 (EDIS Equipo de Investigación Sociológica et al., 1998), se constataba que la tasa de desescolarización era más alta cuanto más grave se hacía la pobreza. De hecho, el atributo con más peso para la salida del sistema educativo es el origen social del alumno (Fernández Enguita, Mena y Riviere, 2010: 71). Según los resultados del informe PISA 2003 analizados por Fernández Enguita, Mena y Riviere (2010), alrededor del $45 \%$ de los/as hijos/as de padres con ocupaciones manuales cualificadas y no cualificadas tienen un riesgo elevado de fracaso escolar, y una tendencia similar se puede apreciar en relación con el nivel educativo de los padres (ibídem: 74). El riesgo de fracaso escolar afecta al $63 \%$ de los/as hijos/as de padres sin estudios y al $46 \%$ de aquellos/as que sólo poseen el título de primaria (ibídem: 75). Entre quienes abandonan la ESO, más del $75 \%$ son hijos/as de padres que no tienen estudios o han alcanzado la educación obligatoria (ibídem: 76). Estos datos no dejan lugar a dudas: las diferencias en el rendimiento escolar pueden estar relacionadas con el origen social.

En el caso de Cádiz, la gran mayoría de alumnado absentista en riesgo de fracaso escolar se sitúa en familias con bajo nivel educativo y de cualificación laboral. Prácticamente el $80 \%$ de los padres de los/as niños/as y adolescentes del Programa de Absentismo Escolar poseen un nivel educativo bajo. El techo educativo se encuentra en la educación obligatoria. Similares porcentajes arroja la cualificación laboral. Suelen ser trabajadores manuales no especializados, y una parte de los ingresos de la unidad familiar se complementa con ayudas de los servicios sociales (Delegación Municipal de Asuntos Sociales, 2012b).

Otra serie de datos interesantes de analizar y presentar son las tasas de desempleo y su relación con el nivel educativo. Como es sabido, el paro y el nivel educativo se relacionan de forma inversa, es decir, a mayor nivel educativo menores tasas de paro. Por ejemplo, en el último trimestre de 2012 de los cerca de 6 millones de desempleados que había en España, el $55 \%$ habían llegado, como máximo, a los estudios de enseñanza obligatoria y, a su vez, este dato se relaciona con el paro juvenil, que llegaba al $52 \%$ (Martín Urriza, 2013: 48-50).

También se produce un salto cuantitativo importante entre aquellos que tienen como techo educativo la ESO y son mayores de 31 años, grupo que suponía el $38 \%$ de los parados. En el caso de quienes están cerca de los 30 años o superan esa edad, el abandono precoz de los estudios puede ser consecuencia de la burbuja inmobiliaria. Éste ha sido y será un gran riesgo: alimentar una economía basada en dos sectores productivos, la construcción y la hostelería, muy extensiva en mano de obra, pero de baja cualificación, coyuntural y estacional. Los jóvenes dejaban de estudiar con un salario asegurado, se embarcaban en proyectos familiares y compraban casas. Ahora engrosan las filas del paro, tienen cargas familiares y corren el peligro de perder sus casas e incorporarse a las filas de la exclusión social.

Encontrarse en la calle y poseer un bajo nivel educativo también son dos factores muy relacionados. En este caso, el 5,7\% de las personas sin hogar en

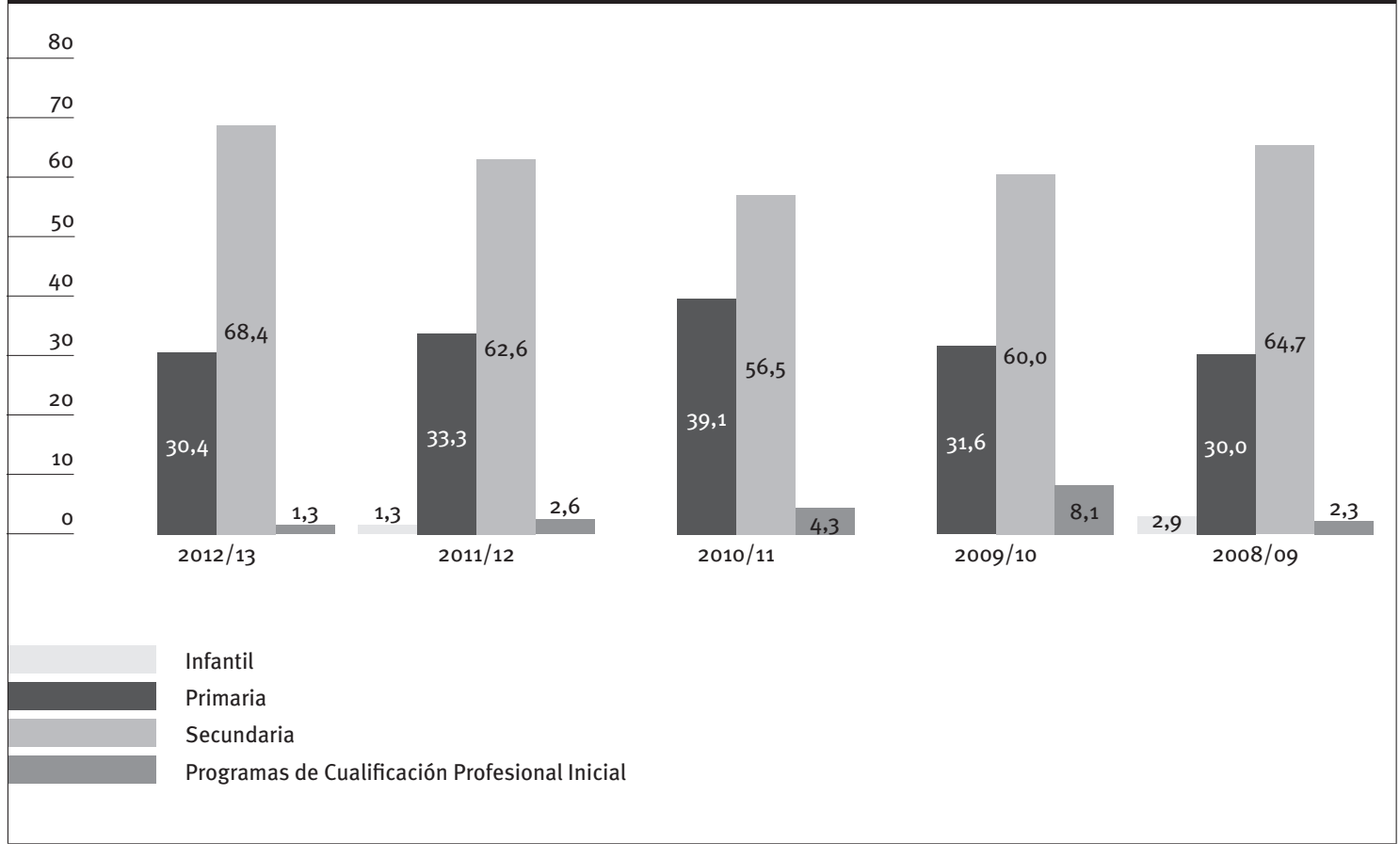

Fuente: Delegación Municipal de Asuntos Sociales (2012b). 
España no tienen estudios, el 11,8\% tienen estudios superiores y el grueso de las personas sin hogar se acumula entre quienes tienen estudios de primaria $(22,2 \%)$ y secundaria $(60,3 \%)$ [INE, 2012b]. Es decir, más del $80 \%$ de los excluidos graves sólo han llegado, como máximo, a la educación obligatoria.

Por otro lado, la edad media de abandono de los estudios en este grupo es de 15,5 años (INE, 2012b), de forma que dicho abandono tiene lugar durante secundaria. Este dato es congruente con el mayor porcentaje de alumnos con problemas en Cádiz: cerca del $65 \%$ de los casos se sitúan en secundaria y ese mismo porcentaje abarca al alumnado de entre los 14 y los 16 años (Delegación Municipal de Asuntos Sociales, 2012b). La edad a la que se produce el abandono de los estudios entre el alumnado gaditano es prácticamente idéntica a la edad en que se produce entre las personas sin hogar en España.

Sobre el abandono de los estudios, comentaba uno de los psicólogos del Programa3 que: “con el panorama que se presenta en sus casas..., que abandonen los estudios puede que sea el menor de sus problemas". Aunque esto sea así y existan otros problemas más graves que acechan, lo cierto es que la desvinculación del sistema educativo implica muchas limitaciones para el futuro. Primero, porque en el ámbito laboral, en la mayoría de los casos, los empujará a la precariedad y el desempleo. Segundo, porque comienzan a mantener una relación de dependencia respecto al sistema, en lugar de como ciudadanos con derechos, servicios y opciones. También porque, de esta forma, en estos colectivos se truncan las pocas posibilidades de movilidad social ascendente que pudieran tener, o por lo menos, de mantenerse y no desplomarse más en la escala social. Es cierto que la educación ya no es el mecanismo que era en otros tiempos para escalar en la pirámide social, pero, para estas poblaciones, puede que sea de los pocos medios lícitos que tengan a su disposición. Ya lo postulaba Merton en su clásico Teoría y estructura sociales, al referirse al concepto de anomia y su tipología (Merton, 2002: 209-239).

Mencionar a Merton permitirá la transición hacia otra dimensión estructural muy importante: la determinada por los comportamientos culturales. El sociólogo americano consideraba que un acto desviado puede ser una adaptación normal de una persona corriente a un sistema desajustado entre medios y fines. Explica que los fines culturales son muy difíciles de conseguir o que están muy limitados por una estructura social desigual y, por otro lado, que los medios legítimos no presentan la misma disponibilidad para todos los individuos. Cuando la presión social impele a la búsqueda de objetivos inalcanzables, aparecen tensiones, sobre todo, entre los peor situados, porque rápidamente se advierte y se experimenta la imposibilidad de la meta.

3 Se utilizará genéricamente el término ‘psicólogo' para referirse a cualquier terapeuta del programa.
Cuando la estructura cultural y la social están mal unificadas, exigiendo la primera una conducta y unas actitudes que la segunda impide, hay una tendencia al quebramiento de las normas, hacia la falta de ellas (ibídem).

Puede haber acuerdo respecto a los objetivos, pero la desigualdad de oportunidades provocará que muchos individuos o grupos generen medios acordes a sus posibilidades. En este caso, serían medios eficientes, pero, posiblemente, ilegítimos e ilegales: sería el tipo II de adaptación anómica de Merton, de innovación.

Más acorde para este trabajo sería el tipo IV de adaptación, de retraimiento. Estos individuos han rechazado los fines culturales y su conducta se sitúa fuera de las normas convencionales de la sociedad. Son los excluidos extremos, los sin techo, los drogodependientes, los enfermos mentales. Estas personas han fracasado, y después de jugar fuerte emocionalmente, consintieron en suscribir las metas y los medios sin obtener las recompensas prometidas. Sin embargo, no pueden recurrir a los medios ilegales, porque fueron socializados en la asimilación del orden normativo y se ven incapaces de transgredirlo. La contradicción se resuelve renunciando a medios y fines:

La pasividad de los padres se convierte en un círculo vicioso, los hijos la reproducen, y claro, es normal que en la escuela no vayan bien. Al final, ese pasotismo los lleva fuera del sistema educativo en la secundaria, la mayoría de las veces sin el título académico (psicólogo de la Delegación Municipal de Asuntos Sociales del Ayto. de Cádiz).

Hay muchas formas de sentirse extraño, diferente, separado y excluido de los demás. El ámbito económico es central, pero no determinante. Por ejemplo, sobran casos de personas con grandes recursos económicos que no tienen problemas ni sensación de sentirse excluidos. No obstante, a una escala más cotidiana, tenemos casos de grupos o colectivos que no tienen necesidades económicas, pero están separados, se han apartado o los hemos distanciado de la mayoría 'normal'. Entre estas variables de exclusión, encontramos todas las que definen como 'diferente' a una persona: la etnia o raza, la lengua, la religión, la cultura, o el nivel de educación e instrucción.

Entre las personas sin hogar en España, el 45,8\% son extranjeras (INE, 2012b). En este grupo predominan los africanos (56,6\%), que, por otra parte, son los que presentan, física y culturalmente, mayor diferencia con los autóctonos. No se conoce ni reconoce su idioma, su religión ni su cultura. Además, como es en el caso de los musulmanes, hay una historia pasada de enfrentamientos, conquistas y reconquistas que forjan muchas imágenes y estereotipos respecto a ellos.

Determinadas comunidades que tienen lazos muy apegados a su tradición presentan niveles de abandono escolar temprano mucho más elevados. 
El caso de los gitanos es paradigmático en este sentido, por sus características extremas (Fernández Enguita, Mena y Riviere, 2010: 84). Otro factor que aumenta las posibilidades de fracaso escolar es ser inmigrante, concretamente, del Sur. En la migración hay tres aspectos que, combinados, multiplican las posibilidades de fracaso escolar: a) el mismo proceso migratorio, con el choque cultural que conlleva, que es especialmente traumático para los adolescentes; b) la lengua; y c) los procesos educativos y de socialización que portan los adolescentes desde sus países de origen (aprendizajes, competencias, costumbres, ritmos). En cuanto al riesgo de fracaso escolar, entre los autóctonos llega a cerca del $35 \%$, mientras que entre los alóctonos sobrepasa el $55 \%$. Igualmente, si se compara a los que han repetido, los autóctonos lo han hecho en un $28 \%$ de los casos y los alóctonos en un $35 \%$ (ibídem: 86). Igualmente, los extranjeros tienden a abandonar su formación antes que los españoles: cerca del $80 \%$ lo hace entre el primer y el segundo ciclo de la ESO, mientras que entre los españoles esa cifra se aproxima al $40 \%$, es decir, la mitad (ibídem: 88).

Dentro de los procesos de exclusión, la inmigración o las minorías étnicas pueden tener cierto protagonismo, y por esta razón se señalan, pero están poco presentes en Cádiz, donde además, están integradas, ya que la ciudad no presenta guetos, suburbios ni poblados chabolistas. La razón es simple: es una isla y carece de espacio.

\subsection{Dimensión relacional}

La dimensión relacional se vincula a las relaciones sociales interpersonales y a los estilos de convivencia en sociedad, es decir, a toda la serie de situaciones que pueden devenir de las interacciones entre las personas, sus redes sociales y los sistemas de sostén social de las comunidades.

Robert Castel (1998: 467-472) llama 'procesos de desafiliación' a las situaciones que se producen a lo largo del tiempo y que van destensando los nudos de las redes sociales. Progresivamente, el individuo se sumerge en un estado de desapego social y alejamiento del ámbito productivo. Es un desligamiento social de gran profundidad y, en cierta forma, está relacionado con el concepto de alienación. El autor llama a este fenómeno el 'paradigma del individualismo negativo', y corresponde al sentimiento de encontrarse alejado, ajeno y extraño en la sociedad que les ha tocado vivir. La sociedad moderna se puede interpretar, en este sentido, como el camino hacia el individualismo: desde lo comunitario y colectivo hacia el protagonismo del individuo, como un ser moral, autónomo, independiente y no esencialmente social. En el individualismo capitalista actual, el patrón podría ser una persona dueña de su empresa y su destino, que trabaja en libre competencia por su propio interés y que rechaza las formas colectivas de encuadramiento o desconfía de ellas, llámense partidos políticos, sindicatos, asociaciones. Un indi- viduo sujeto de derechos y deberes bajo un sistema contractual basado en un acuerdo voluntario y tácito entre seres autónomos e independientes, en cambio, sería el individualismo positivo.

Sin embargo, se ha ido esparciendo subrepticiamente otro individualismo, negativo, que se define en términos de falta de seguridad, de bienes, de vínculos, de atención, de derechos y de deberes en la práctica. El vagabundo es su paradigma. Su forma de individualismo es la independencia completa, la enajenación y disociación total del contrato social. Es un individualismo que se define por falta de marcos, no por la búsqueda de intereses. Este proceso de desafiliación del que habla Castel es especialmente grave cuando se produce en el seno de la familia durante la infancia y la adolescencia. Sobre todo, si estamos hablando de las familias con las que interviene el Programa de Absentismo y Fracaso Escolar en Asuntos Sociales, ya que al tratarse de un menor, la familia es un cauce obligado para la intervención. La mayoría son familias desestructuradas, es decir, con muchas carencias tanto económicas como sociales, culturales o relacionales. Son familias multiproblemáticas que, por sus características y contexto, pueden clasificarse como de alto riesgo, y por tanto, los menores están en un ambiente conflictivo.

La Encuesta a las Personas sin Hogar (INE, 2012b) incluye una pregunta sobre la situación familiar antes de los 18 años. Estas personas han vivido situaciones familiares muy problemáticas, como muestra el Gráfico 2.
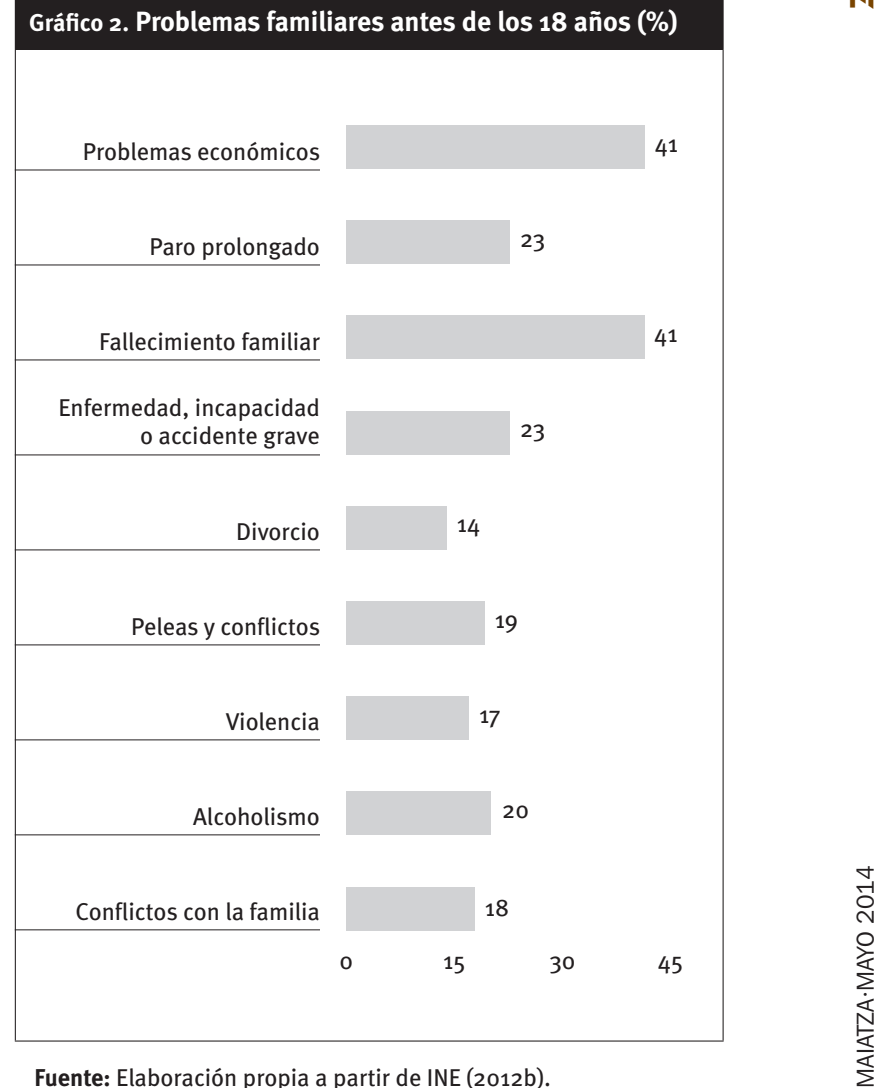

Fuente: Elaboración propia a partir de INE (2012b). 
Muchas de estas situaciones han conseguido que el adolescente sienta un desapego importante a su familia. De hecho, en la misma encuesta se preguntaba por la relación que las personas sin hogar mantenían con su familia: prácticamente no tenían contacto con otros miembros, o con su cónyuge o pareja (Tabla 2). La única excepción eran los hijos: cerca del $60 \%$ declaraba haber mantenido contacto con su hijo/a en el último mes.

Tabla 2. Personas sin hogar que no mantienen contacto con miembros de su familia, según parentesco (\%, respuesta múltiple)

\begin{tabular}{|l|c|}
\hline Miembro de la familia & $\%$ \\
\hline Cónyuge o pareja & 78 \\
\hline Padre & 67 \\
\hline Madre & 51 \\
\hline Hermanos & 41 \\
\hline Hijos & 29 \\
\hline Otros familiares & 71 \\
\hline
\end{tabular}

Fuente: Elaboración propia a partir de INE (2012b).

Por desgracia, la situación familiar conflictiva y multiproblemática es un caldo de cultivo excepcionalmente propicio para lograr que una persona acabe teniendo graves problemas personales, relacionales, psicológicos, educativos, económicos y de diverso tipo, en el futuro. En el caso de las familias sujetas al Programa de Absentismo Escolar en Cádiz, los problemas más importantes con los que se encuentran los menores son los relativos a las drogas o la delincuencia de los padres, presentes en cerca de un tercio de los casos. Además, generalmente, estas situaciones acaban en estancias en la cárcel. Drogas y delincuencia son dos estilos de vida que van muy unidos y tienen un resultado grave de desamparo hacia el menor, ya que la supervisión parental prácticamente desaparece ante la urgencia y la necesidad de satisfacer la adicción, o la ausencia que provoca las temporadas que pasan en prisión y la desestabilización que eso provoca.

Según entrevista mantenida con los psicólogos del Programa, existe otro problema importante que se presenta en las familias y que condiciona el estilo educativo y socializador:

Existe un gran grupo que tiene fuertemente limitadas sus capacidades intelectuales. No es que sean enfermos mentales, o por lo menos no están diagnosticados. Son personas normales, pero es que no saben, no llegan, están en el límite. Así, ante los problemas hacen dejadez, 'pasan de todo', no se enfrentan a ellos, no cogen las riendas de sus vidas y toman decisiones, sino que se quedan en una actitud pasiva, inmóvil, inertes; y entonces, sus problemas y los problemas de sus hijos les pasan por encima (psicólogo de la Delegación Municipal de Asuntos Sociales del Ayto. de Cádiz).
Esta persona seguía argumentando que:

Claro, esto implica otro problema, el de las relaciones sociales, que en un futuro serán las redes y recursos de apoyo de los que carecerá el menor para enfrentarse a situaciones límite de la vida. Las familias no integran a los niños en una vida social que los incluya en actividades, ni en grupos, ni en colectivos diferentes. Las únicas alternativas son, o la casa, que es insoportable, o la calle (psicólogo de la Delegación Municipal de Asuntos Sociales del Ayto. de Cádiz).

Esta indolencia se convierte en un factor de riesgo muy importante cuando hablamos de la infancia y la adolescencia. Según la experiencia de los trabajadores del Programa y la evolución de los casos que presentan esta casuística, los adolescentes tienden al aislamiento. Se limita la relación y la vinculación que se produce a estas edades con los iguales. El adolescente sufre un proceso de etiquetado que lo estigmatiza en sus relaciones y condicionará sus estilos de relación en el futuro. El proceso de etiquetado (Becker: 1971), analizado por el interaccionismo simbólico, en estos casos es importante y clarificador, sobre todo, unido al estudio de la reacción social. Es interesante leer el discurso y luego seguir analizando la importancia de este concepto:

Imagina, como muchos casos que tenemos. Los padres no se ocupan del chico, no lo mantienen aseado, huele mal, la ropa sucia y desaliñado, etc. Esto, ya de por sí, es una situación muy incómoda para el chico, sobre todo, porque tiene la oportunidad de compararse con los demás y no van así. Ahora, el niño coge piojos, y además los puede contagiar. Inmediatamente, el resto de niños lo empiezan a llamar 'el piojoso' y no se querrán relacionar con él. Incluso sus padres les dirán que no se junten con él. Los niños son seres muy sociales; si a esas edades, tú eres el raro, el que no quieren tener cerca, 'el piojoso'. Ese chico comienza a retraerse, a aislarse, y aprenderá a vivir en su mundo propio. Este caso, puede ser perfectamente un candidato perfecto para la desviación o la exclusión (psicólogo de la Delegación Municipal de Asuntos Sociales del Ayto. de Cádiz).

Esa acción individual, el comportamiento de los padres que condiciona la vida del chico, y la reacción social que produce el grupo son factores que pueden construir la desviación y la exclusión. En la formación de la identidad, participa de modo decisivo la reacción de los otros, ya que la construcción de la identidad es un proceso social. Las personas a quienes se aplica la etiqueta de desviado aumentan sus posibilidades de consolidar la desviación por las consecuencias que ello tiene para su autoimagen y su imagen social. La etiqueta facilita los futuros comportamientos desviados, sería una vía de desviación y exclusión. El proceso es el siguiente: desviación $\longrightarrow$ sanción social $\longrightarrow$ desviaciones secundarias $\longrightarrow$ hostilidad al sancionador $\longrightarrow$ enfrentamiento $\longrightarrow$ identificación o estigmatización social $\longrightarrow$ 
fortalecimiento y aceptación del estatus (Cid Moliné y Larrauri, 2001: 202-209). Al final, es la profecía que se autocumple.

\subsection{Dimensión individual}

Los elementos de carácter individual que intervienen en estos procesos son tanto los relativos a la adscripción personal (edad, sexo, personalidad, raza) como los adquiridos a través de las vivencias y estilos de vida (adicciones, antecedentes penales, separaciones y divorcios) [Sánchez Morales, 1999: 40]. A escala individual, además de las variables anteriores, podemos definir los condicionantes que afectan a estas personas haciéndolas precipitarse hacia la exclusión como sucesos vitales estresantes. Los sucesos vitales estresantes harían referencia a situaciones de profunda gravedad emocional. Son momentos en los que psicológicamente nos encontramos hundidos, por ejemplo, el fallecimiento traumático de un ser querido, la enfermedad, las adicciones, la delincuencia/cárcel, el desempleo, las rupturas familiares o relacionales. Muchos estudiosos apoyan la idea de que lo significativo en las personas sin hogar es que suelen vivir una serie de sucesos vitales estresantes superior a la media del resto de personas (Muñoz, Vázquez y Vázquez, 2003).

Estos sucesos se acumulan a lo largo de los primeros años de vida y la juventud, y marcan negativamente las trayectorias vitales de los sujetos. De hecho, las personas sin hogar han sufrido, de media, cinco experiencias graves en su vida antes de cumplir los treinta años (Cabrera, Malguesini y López, 2002: 177). En esta línea, cabe apuntar que el $30 \%$ ya ha pasado por alguna experiencia negativa en su primera infancia (hasta los 10 años), cuando más vulnerables somos. Han pasado por situaciones muy difíciles y los recursos de los que dispone la sociedad no han sido suficientes para prevenir o minimizar el choque de esos sucesos en sus vidas. Se podría argumentar que el sinhogarismo no sólo es un problema personal, sino un fracaso de las instituciones y los servicios de prevención y atención ante estos momentos críticos en la vida de las personas.

Los chicos y chicas incluidos en los programas de Asuntos Sociales van por ese camino. En cerca de un $30 \%$ de los casos, sus padres tienen o han tenido problemas graves con las drogas y alrededor de un quinto del total han tenido problemas con la Justicia que a menudo han terminado en el ingreso en prisión. Como se comentaba anteriormente, otro tercio sufre problemas de abandono, desidia o apatía con respecto a la educación y crianza de sus hijos, y en un $25 \%$ de los casos el padre ha desaparecido 0 ha dejado de atender sus obligaciones paternas; en estas circunstancias, las mujeres solas han tenido que llevar el hogar, la mayoría de las veces con limitadísimos recursos.

Este panorama es desalentador para los profesionales, pero más aún para los propios protagonistas, que, si se cumplen las tendencias estadísticas, acabarán engrosando las filas de los desviados, marginados o excluidos. También hay que decir que, si bien todos los fracasos y abandonos escolares no tienen por qué acabar en el sinhogarismo, casi todas las personas sin hogar han abandonado los estudios a edad temprana.

\section{Conclusiones}

En los últimos años, se han detectado tres retos en materia de infancia y exclusión (Clua-Losada, Sessé y Tur, 2011: 83), que se concretan en la formación, la prevención y coordinación de los servicios que atienden a estos colectivos. En este apartado de

Tabla 3. Sucesos vitales estresantes en personas sin hogar, según el periodo de la vida en el que ocurren (\%, respuesta múltiple)

\begin{tabular}{|c|c|c|c|c|c|c|c|}
\hline \multicolumn{2}{|l|}{ <10 años } & \multicolumn{2}{|c|}{ 10-20 años } & \multicolumn{2}{|l|}{$20-30$} & \multicolumn{2}{|l|}{ 30-40 años } \\
\hline Suceso & $\%$ & Suceso & $\%$ & Suceso & $\%$ & Suceso & $\%$ \\
\hline Malos tratos & 21 & Expulsión & 8 & Muerte de la madre & 52 & Muerte de la pareja & 10 \\
\hline $\begin{array}{c}\text { Consumo parental de } \\
\text { drogas }\end{array}$ & 24 & Fuga & 31 & Muerte del padre & 64 & Cárcel & 29 \\
\hline Abandono & 10 & - & - & Alejamiento & 40 & Intento de suicidio & 26 \\
\hline Orfanato & 14 & - & - & Enfermedad física & 42 & Desempleo & 67 \\
\hline $\begin{array}{c}\text { Abandono parental } \\
\text { del hogar }\end{array}$ & 11 & - & - & Enfermedad mental & 13 & Problemas económicos & 71 \\
\hline- & - & - & - & $\begin{array}{l}\text { Ingreso en hospital } \\
\text { psiquiátrico }\end{array}$ & 17 & Pérdida de la vivienda & 16 \\
\hline- & - & - & - & Consumo de drogas & 17 & - & - \\
\hline- & - & - & - & Consumo de alcohol & 47 & - & - \\
\hline
\end{tabular}

Fuente: Cabrera, Malguesini y López (2002: 175-177). 
conclusiones intentaremos hacer algunas sugerencias al respecto.

La diferencia mencionada al principio entre viajero y turista reside en la autopercepción respecto al control de la propia vida y el enquistamiento de la estigmatización. El nómada lo puede ser por propia convicción, pero si su autopercepción incluye la imposibilidad de emprender o retomar un proyecto viable de vida, le resultará muy difícil salir del círculo de la autoexclusión en el que se mantiene. Asimismo, no podrá intervenir sobre otras cuestiones que tienen relación con su propia vida y las personas que entran en ella. Le será más difícil ilusionar a su pareja o hijos, o recrear un posible futuro para ellos. El horizonte social cerrado, por tanto, entra dentro de las posibilidades más difíciles de variar si se trata de una consideración de incapacitación personal. Desafortunadamente, esta falta de proyecto de futuro incide de nuevo sobre los menores.

La inmigración, uno de los factores que incide en el resultado de la exclusión, provoca efectos que no siempre terminan resolviéndose: la desagregación familiar es un hecho en la provincia de Cádiz (Robles Gavira y Pérez-González, 2014). La inmigración que conduce a la exclusión descompone las familias hombres o mujeres que se instalan solos hasta que pueden reunir al resto de sus miembros-y esto, a su vez, incide sobre la socialización de los menores y el sentimiento de desapego.

La desafección, o las relaciones difusas e intermitentes de las que dan cuenta sociólogos como Castel (1998) o Bauman (2005 y 2007), forman parte también de una sociedad compleja y de cambios. Hemos aludido al fracaso de las instituciones y las políticas en cuestiones tales como el sinhogarismo. Es evidente que las instituciones de atención en el Estado del bienestar se crean para regular y atender cuando existen problemas. Si la atención se destina sobre todo al mantenimiento y no a la subsanación de carencias, los organismos encargados deben cuestionar y evaluar su función. Es cierto que también en momentos de crisis estas cuestiones se multiplican, aparecen 'nuevos pobres' y, por tanto, nuevos excluidos en todos los planos: en el laboral, y por sus efectos, también en el escolar.

El desapego en la red de relaciones y en la socialización es una de las cuestiones sobre las que habría que trabajar, no sólo por la falta de los efectos sociales, sino por la temida producción de una socialización ineficaz que conduzca directamente a situaciones de exclusión y, como hemos dicho, de autoexclusión. Esta última se experimenta, si cabe, más aún en la escuela. Deshacer la cadena de absentismo/fracaso y abandono de la exclusión social debería ser también una cuestión vinculada con la institución escolar. Si las escuelas no pueden hacer nada por ayudar en la desigualdad social, al menos sí podrán hacerlo en relación a las carencias socializadoras y al autoconvencimiento que algunos terminan perteneciendo a la clase de los excluidos. Pero de momento, las instituciones escolares sólo son 'delatoras' de lo que ya es evidente: cuando los niños y niñas en las escuelas están en situaciones difíciles, insostenibles, que se ven reflejadas tanto en su comportamiento como en los resultados, sus técnicos no hacen sino avisar a otros técnicos (los servicios sociales de los ayuntamientos) de que se da esta situación. 0 se hacen adaptaciones específicas, centrándose en cuestiones escolares, cuando lo que deberían hacer sería actuar de forma integral sobre las raíces de los problemas. La cuestión es que 'esos problemas' están excesivamente compartimentados y, por tanto, la resolución es más complicada.

Sólo en algunos casos se ha avanzado en la difícil relación familia-escuela. Un ejemplo son los compromisos educativos que se hacen firmar a los padres y madres para que retomen las tareas de formación de su prole. Es decir, estamos planteando que se deben diseñar nuevas estrategias para que estos 'nuevos excluidos' comiencen a caminar y que éstas deberían centrarse en la relación familia-escuela, trabajando quizá en una tutorización más cercana en el caso de estos niños y niñas en riesgo de exclusión y autoexclusión. Entonces la escuela cumpliría su función social socializadora. 
BAUMAN, Z. (2007): Modernidad líquida, Buenos Aires, Fondo de Cultura Económica (1aㅡ ed.: 2000).

- (2005): Amor líquido: acerca de la fragilidad de los vínculos humanos, México D. F., Fondo de Cultura Económica.

BECKER, H. (1971): Los extraños, Buenos Aires, Amorrortu.

BOWLES, P. (1992): El cielo protector, Barcelona, RBA (1 1 ed.: 1949).

CABRERA, P.; MALGESINI, G.; y LÓPEZ, J. A. (2002): Un techo y un futuro. Buenas prácticas de intervención social con personas sin hogar, Barcelona, Icaria.

CARITAS DIOCESANA DE CÁDIZ Y CEUTA (2012): Memoria del Centro de Día de Personas sin Hogar 'Luz y Sal'; Cáritas Diocesana de Cádiz y Ceuta; Hijas de la Caridad de San Vicente de Paúl.

CÁRITAS ESPAÑOLA (2012): “La red de acogida de Cáritas constata un aumento de la pobreza, la desigualdad y la injusticia social", 24-092012 [<http://www.caritas.es/noticias_tags_ noticialnfo.aspx? Id=6017〉].

CASTEL, R. (1998): La metamorfosis de la cuestión social. Una crónica del salariado, Barcelona, Paidós.

CID MOLINÉ, J.; y LARRAURI, E. (2001): Teorías criminológicas, Barcelona, Bosch.

CLUA-LOSADA, M.; SESSÉ, A.; y TUR, M. (2011): “Infancia y exclusión social en España: realidades y retos a partir de la crisis", Zerbitzuan, $\mathrm{n}^{0}$ 50, págs. 71-84 [<http://dx.doi.org/doi:10.5569/11347147.50.06)].

DELEGACIÓN MUNICIPAL DE ASUNTOS SOCIALES (2012a): Memoria del Centro de Acogida, Cádiz, Ayuntamiento de Cádiz.

- (2012b): Memoria del Programa de Absentismo Escolar. Curso 2012/13, Cádiz, Ayuntamiento de Cádiz.
EDIS EQUIPO DE INVESTIGACIÓN SOCIOLÓGICA et al. (1998): Las condiciones de vida de la población pobre en España. Informe General, Madrid, Fundación Foessa; Cáritas.

FEANTSA (2005): Tipología Europea de Sin Hogar y Exclusión Residencial ETHOS, Federación de Entidades de Apoyo a las Personas sin Hogar [rhttp://www.feantsa.org/spip. php?action=acceder_document\&arg $=831 \&$ cle $=855$ b5 db383c68b209672204bfo2faf 3cc4cacaog\&file=pdf\%2Fethos_spain-2. pdf\&lang=en〉].

FEDERACIÓN DE ENTIDADES DE APOYO A LAS PERSONAS SIN HOGAR (2011): Por la elaboración de una estrategia estatal para la prevención y erradicación del sinhogarismo. Propuestas a los partidos políticos (elecciones generales en el Estado español), Federación de Entidades de Apoyo a las Personas sin Hogar [<http:// www.provivienda.org/wordpress/wp-content/ uploads/2011/09/FEPSH_2011.pdf>].

FERNÁNDEZ ENGUITA, M.; MENA MARTÍNEZ, L.; y RIVIERE, J. (2010): Fracaso y abandono escolar en España, Barcelona, Fundación La Caixa.

JUNTA DE ANDALUCÍA (2003): "Plan Integral para la Prevención, Seguimiento y Control del Absentismo Escolar", Boletín Oficial de la Junta de Andalucía, no 235, 5-12-2003, [khttp://www. juntadeandalucia.es/boja/2003/235/d6.pdf>; véase también 〈http://www.juntadeandalucia. es/averroes/ies_macarena/pdc/proyecto/ absentismo/planabsentismo.pdf $\rangle$ ].

INSTITUTO NACIONAL DE ESTADÍSTICA (2012a): Encuesta de Población Activa [<http://www.ine.es/jaxi/ menu.do?type $=$ pcaxis $\&$ path $=/ \mathrm{t} 22 /$ e308_ mnu\&file $=$ inebase $\& L=0>$. 
- (2012b): Encuesta sobre Personas sin Hogar [rhttp:// www.ine.es $/$ jaxi $/$ menu.do? $\mathrm{L}=0 \&$ type $=$ pcaxis \& path $=\% 2 \mathrm{Ft} 25 \% 2 \mathrm{Fp} 454 \&$ file=inebase $>$.

- (2009-2012): Encuesta de Condiciones de Vida [<http://www.ine.es/jaxi/ menu.do?type $=$ pcaxis $\&$ path $=/ \mathrm{t} 25 /$ p453\&file=inebase $)$.

MARTÍN URRIZA, C. (2013): "Paro y desigualdad: la desigualdad construida", Revista Temas, n- 218-219, págs. 48-50.

MERTON, R. K. (2002): Teoría y estructuras sociales, México D.F., Fondo de Cultura Económica (1ae ed.: 1949).

MUÑOZ, M.; VÁZQUEZ, C.; VÁZQUEZ, J. J. (2003): Los límites de la exclusión. Estudio sobre los factores económicos, psicosociales y de salud que afectan a las personas sin hogar en Madrid, Madrid, Témpora.

MUÑOZ DEL BUSTILLO, R. (2013): “La gran brecha: desigualdad personal de la renta en España", Revista Temas, nํㅜ 218-219, págs. 25-28.
PÉREZ-GONZÁLEZ, A. B.; y ROBLES GAVIRA, G. (2012): "Camino a la exclusión. Relaciones entre el fracaso y abandono escolar y los procesos de exclusión social severa" [comunicación], IV Encuentro Internacional con Menores en Contextos de Riesgo. Tetuán, 23/28-09-12 [〈http://hdl.handle.net/10498/15702〉].

ROBLES GAVIRA, G.; y PÉREZ-GONZÁLEZ, A. B. (2014): "Images and significant aspects of the integration of immigrants in the Western Mediterranean. The unsaid: The two sides of immigration" [comunicación], III. European Conference on Social and Behavioral Sciences, 6/8-2-2014, Sapienza Università di Roma.

SÁNCHEZ MORALES, M. R. (1999): La población 'sin techo' en España: un caso extremo de exclusión social, Madrid, Sistema.

SUBIRATS, J. (dir.) (2005): Análisis de los factores de exclusión social, Bilbao, Fundación BBVA.

TEZANOS, J. F. (2008): La sociedad dividida. Estructura de clases y desigualdades en las sociedades tecnológicas, Madrid, Biblioteca Nueva. 